\title{
Fundamental Investigation on Seismic Retrofitting Method of Aging Concrete Structural Wall Using Carbon Fiber Sheet-Constitutive Law of Rectangular Section
}

\author{
Kazuhiro Hayashi $\mathbb{D}^{1},{ }^{1}$ Tomoya Matsui, ${ }^{1}$ Taiki Saito, ${ }^{1}$ and Roy Reyna ${ }^{2}$ \\ ${ }^{1}$ Department of Architecture and Civil Engineering, Toyohashi University of Technology, Toyohashi 441-8580, Japan \\ ${ }^{2}$ Faculty of Civil Engineering, National University of Engineering, Lima 15333, Peru \\ Correspondence should be addressed to Kazuhiro Hayashi; hayashi.kazuhiro@forest.ocn.ne.jp
}

Received 27 June 2019; Revised 11 February 2020; Accepted 24 February 2020; Published 31 March 2020

Academic Editor: Mohammad A. Hariri-Ardebili

Copyright (c) 2020 Kazuhiro Hayashi et al. This is an open access article distributed under the Creative Commons Attribution License, which permits unrestricted use, distribution, and reproduction in any medium, provided the original work is properly cited.

\begin{abstract}
Aging building structure has become a world problem. This problem is particularly serious in developing and underdeveloped countries. The multihazard resilience and sustainability (e.g., seismic performance) decrease at the aging building. A construction method for strengthening aging-reinforced concrete buildings by wrapping structural members with carbon fiber sheets has been proposed and implemented in recent years. Authors aim to develop a seismic retrofitting method of aging concrete structural wall with a rectangular cross section using carbon fiber sheets. In this paper, authors examined the stress-strain relationship of concrete elements with rectangular cross sections reinforced by wrapping with carbon fiber sheets. Monotonic uniaxial compression tests were performed on 21 specimens using the ratio of the long side to the short side and the ratio of the element height to the short side of the concrete cross section, the weight of the carbon fiber sheet, and the chamfer radius of section corners as variables. The tests revealed that (1) the compressive strength decreases and ultimate strain increases as the ratio of the long to short side (longitudinal ratio) of the cross section increases even in a range the ratio exceeds 2 and (2) the ratio of the element height to the short side does not significantly affect the stress-strain relationship. Furthermore, authors proposed evaluation formulas for the constitutive law of concrete elements with rectangular cross sections including the longitudinal ratio which exceeds 2 reinforced by carbon fiber sheets and confirmed that the formulas can reproduce the test results with good accuracy.
\end{abstract}

\section{Introduction}

A construction method for strengthening aging-reinforced concrete buildings against earthquakes by wrapping structural members with carbon fiber sheets (CF sheets) has been proposed and implemented in recent years [1-4]. It was conventionally believed that seismic reinforcement using $\mathrm{CF}$ sheet jackets (CF reinforcement) is applicable to beam and column members with circular $[5,6]$ or nearly square [7-9] cross sections and beam-column connections [10]. Lorenzis and Tepfers [5] proposed an evaluation formula for the axial strain at peak stress of FRP-confined concrete cylinders. Carey and Harries [6] presented the recommendations for modeling and designing of axially loaded circular confined concrete. Zhuang et al. [7] repaired the seriously damaged
RC beam specimens with CFRP and was verified the seismic performance experimentally. Lee et al. [8] presented the sectional renovation of RC beam members using CFRP composites. Ercan et al. [9] clarified experimentally that the reinforced concrete beam-column connections strengthened with carbon fiber-reinforced plastic (CFRP) sheets increase the bearing capacity and ductility. In recent years, new-type mixed structure connection consisting of the reinforced concrete column and steel beam (RCS) is developed [10]. Reinforcement with the CF sheet can be applied easily to mixed structures. So, the method had not been used on walls or other cross sections with extremely large aspect ratios. The authors have proposed seismic retrofitting using the wrapping method of structural members with CF sheets for the problem of flexural failure in aging columnless 
multistory shear walls found in the 2010 Chile Earthquake and others and have verified the method's effectiveness using static loading tests $[11,12]$.

To design the CF reinforcement, the constitutive law of materials of the concrete element confined by the CF sheet (i.e., stress-strain relationship) has to be estimated. Most of the past studies [13-18] propose evaluation formulas for the constitutive law of CF-reinforced concrete elements with circular or square cross sections. Pessiki et al. [14] presented the experimental results of the axial loading behavior of circular and square concrete specimens confined with fiberreinforced polymer (FRP) composite jackets. Nakatsuka et al. [13] and Lam and Teng [15] proposed a stress-strain model for carbon fiber sheet-confined concrete with a circular and square section based on the monotonic compression tests. Harries and Carey [16] investigated the effect of the gap between the concrete and confining FRP jacket and proposed a stress-strain relationship considering this effect. Lam and Teng [17] proposed a stress-strain model of FRP-confined concrete under cyclic compression loading. Mahdavi et al. [18] proposed the optimise design procedure (algorithm) of the seismically retrofitting reinforced concrete structures based on the stress-strain relationship of square column cross section with FRP. Some studies also consider rectangular cross sections [19-24]. Lam and Teng [19] and Ouyang and Liu [20] proposed a stress-strain model for the FRP-confined concrete of the rectangular columns. Wang et al. [22] presented the analysis models of the reinforced concrete frame (rectangular cross section) strengthened with carbon fiber-reinforced polymer (CFRP) sheets. However, the ratio of the long to short side (longitudinal ratio) on these studies is around 2, and wall members are beyond their scope of application. Triantafillou et al. [24] used compression test specimens of FRP-confined concrete elements with the longitudinal ratio exceeding 4 . They proposed the evaluation method of a compressive strength but not a stress-strain relationship (especially postpeak behavior).

When concrete elements with circular cross sections are reinforced with $\mathrm{CF}$, the confinement effect increases compressive strength and improves ductility capacity as discussed by Lam and Teng [15]. However, for rectangular cross sections, the confinement effect is not as large as in round sections. When the chamfer radius of section corners is small, ductility improves but the strength may not increase as discussed by Nakatsuka et al. [13]. Moreover, the confining effect of the CF sheet is further reduced when the longitudinal ratio is larger as discussed elsewhere [20, 23]. The maximum ratio of the long to short side on the previous studies is around 2. Thus, the constitutive law cannot be estimated based on previous studies of concrete elements when the CF reinforcement is applied to wall members.

In this paper, authors conducted uniaxial compression tests using the amount of fiber reinforcement, the ratios of the long side and height with respect to the short side of the cross section, and the chamfer radius of section corners as variables in order to shed light on the confinement effect of $\mathrm{CF}$ sheets on rectangular concrete sections and to empirically show their stress-strain relationships. Furthermore, in order to apply to rectangular cross sections designed as wall members as well, authors expanded the constitutive law suggested in a previous research [13] and derived evaluation formulas with explicit functions for effective confinement area and longitudinal ratio of the concrete element.

\section{Evaluation Formulas for the Constitutive Law of CF-Reinforced Concrete}

2.1. Monotonically Increasing Model of Stress-Strain Relationship. ACI Committee 440 [23] gives the stressstrain relationship shown in Figure 1 for the constitutive law of materials of concrete elements reinforced with $\mathrm{CF}$. The linear quadratic slope $E_{2}$ and strain at ultimate state $\varepsilon_{c c u}$ in Figure 1 are calculated from the cross-sectional quantities of the concrete element and CF sheet used for reinforcement. In addition to concrete elements with circular and square cross sections, the scope includes rectangular cross sections with longitudinal ratios not greater than 2 . For the rectangular cross sections, the confinement effect of CF reinforcement is affected by the chamfer radius of section corners. In the ACI model, the effective confinement area ratio $\alpha_{e}$ of the concrete element confined by the CF sheet (see Figure 2) is estimated by the following equation, which reflects the evaluation based on the material constitutive law:

$$
\alpha_{e}=\frac{A_{\mathrm{e}}}{A_{\mathrm{c}}}=\frac{1-\left(\left[b / d(d-2 R)^{2}+d / b(b-2 R)^{2}\right] / 3 A_{\mathrm{g}}\right)-\rho_{\mathrm{g}}}{1-\rho_{\mathrm{g}}},
$$

where $b$ is the shorter dimension of the cross section, $d$ is the longer dimension, and $R$ is the chamfer radius of section corners (see Figure 2). Also, $A_{c}$ is the area of the cross section, $A_{\mathrm{e}}$ is the effective confinement area of the CF sheet, $A_{\mathrm{g}}$ is the total cross-sectional area of the concrete element (equal to $A_{\mathrm{c}}$ without steel rebars), and $\rho_{g}$ is the ratio of reinforcement.

The ACI model has a monotonically increasing stressstrain relationship, in which the stress continues to increase until the concrete element reaches the ultimate state under compressive forces (see Figure 1). However, it has been noted that the stress-strain relationship does not necessarily increase monotonically when the CF sheet confinement is inadequate (such as when the chamfer radius is small with respect to cross-sectional dimensions) or when the longitudinal ratio of the element is large. This phenomenon is discussed elsewhere $[13,20]$.

\subsection{Maxima Model of Stress-Strain Relationship.} Nakatsuka et al. [13] proposed a method for evaluating the constitutive law of materials based on a maxima model, in which the slope of the stress-strain relationship becomes negative after reaching compressive strength (Nakatsuka model). The stress-strain relationship of the Nakatsuka model outlined in Figure 3 accommodates both a monotonically increasing model in which the strength uniformly rises until ultimate strain when the CF sheet ruptures and a maxima model in which the compressive strength is reached 


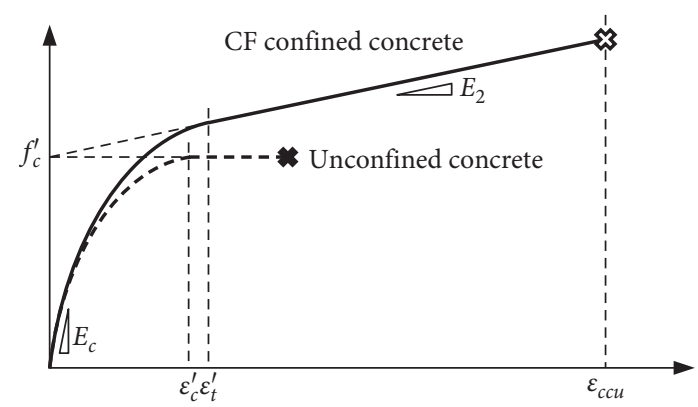

FIGURE 1: Stress-strain relationship of the ACI model.

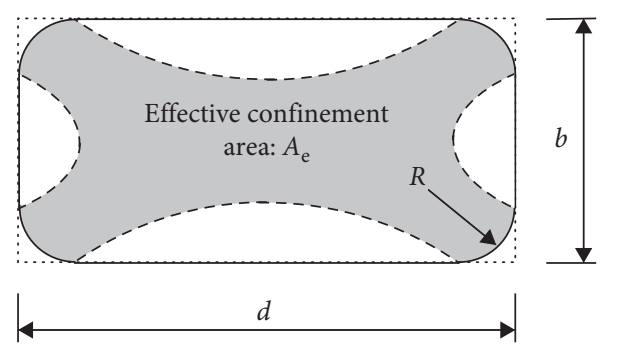

FIgURE 2: Effective confinement area according to the ACI model.

in the range of about 0.25 to $0.5 \%$ axial strain and the strength falls thereafter.

The Nakatsuka model calculates the six components that define the material constitutive law in Figure 3. $\sigma_{B}$ is the compressive strength of concrete elements reinforced with $\mathrm{CF}$ calculated using the evaluation formula as follows:

$$
\sigma_{B}=F_{0}+4 p_{f} E_{f} \varepsilon_{f B} C_{\sigma B},
$$

where $F_{0}$ is the compressive strength of unreinforced plain concrete, $p_{f}$ is the reinforcement ratio of the CF sheet, and $E_{f}$ is Young's modulus of elasticity of the CF sheet. The unit of $\sigma_{B}, F_{0}$, and $E_{f}$ are $\mathrm{N} / \mathrm{mm}^{2}$. Also, $\varepsilon_{f B}$ is given by the following equation:

$$
\varepsilon_{f B}= \begin{cases}0.01\left(1-\frac{1}{\left(\left(F_{0} / 140\right)+1\right)}\right), & F_{0} \leq 60, \\ 0.003, & 60<F_{0} \leq 80 .\end{cases}
$$

$\varepsilon_{B}$ is the strain when the stress reaches $\sigma_{B}$ calculated using the evaluation formula as follows:

$$
\varepsilon_{B}=\varepsilon_{0}+10 \varepsilon_{0} \frac{p_{f} E_{f} \varepsilon_{f B}}{F_{0}} C_{\varepsilon B},
$$

where $\varepsilon_{0}$ is the axial strain for the said compressive strength. $E_{B T}$ is the stiffness of the $2^{\text {nd }}$ region in Figure 3 calculated using the evaluation formula as follows:

$$
E_{B T}=-0.4 E_{0 B T}+\frac{1.4 E_{0 B T}}{C_{E B T}\left(p_{f} E_{f} / 0.06 F_{0}^{2}\right)+1},
$$

where $E_{O B T}$ is given by the following equation:

$$
E_{0 B T}=6000-430 F_{0} \text {. }
$$

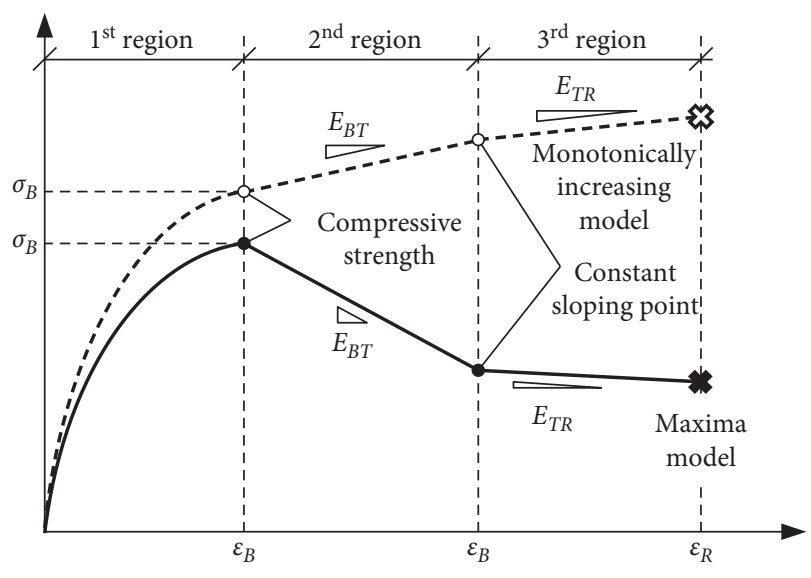

FIGURE 3: Stress-strain relationship of Nakatsuka model.

$\mathcal{E}_{T}$ is the strain of the boundary point between the $2^{\text {nd }}$ region and the $3^{\text {rd }}$ region in Figure 3 calculated using the evaluation formula as follows:

$$
\varepsilon_{T}=\varepsilon_{0}\left(-0.016 F_{0}+2.7\right)+\varepsilon_{0}\left(0.00001 F_{0}+0.0016\right) C_{\varepsilon T} p_{f} E_{f} .
$$

$E_{T R}$ is the stiffness of the $3^{\text {rd }}$ region in Figure 3 calculated using the evaluation formula as follows:

$$
E_{T R}=-0.25 E_{0 B T}+\frac{0.55 E_{0 B T}}{C_{E T R}\left(p_{f} E_{f} / 0.06 F_{0}^{2}\right)+1} .
$$

$\varepsilon_{R}$ is the ultimate strain of concrete elements reinforced with $\mathrm{CF}$ calculated using the evaluation formula as follows:

$$
\varepsilon_{R}=\varepsilon_{0}\left(20 \varepsilon_{f r}+1.2\right)+\varepsilon_{0}\left(1000 \varepsilon_{f r}-3\right) C_{\varepsilon R} \frac{p_{f} E_{f}}{F_{0}^{2}},
$$

where $\varepsilon_{f r}$ is the strain at rupture of the CF sheet. $C$ in equations (2), (4), (5), (7), (8), and (9) is a cross-sectional shape factor based on the cross-sectional shape of the concrete element and is equal to 1.0 in all cases for circular sections. For square sections, $C_{\sigma B}, C_{\varepsilon B}$, and $C_{\varepsilon T}$ are equal to $0.6, C_{E B T}$ and $C_{E T R}$ are equal to 0.4 , and $C_{\varepsilon R}$ is equal to 1.0 .

Nakatsuka et al. [13] performed a number of uniaxial compression tests on concrete elements with CF reinforcement to verify the accuracy of this model. However, the study only considered concrete elements with circular and square cross sections, and the chamfer radius $R$ of squaresectioned specimens was not considered as an experimental variable.

\subsection{Expansion of Evaluation Formulas for the Constitutive} Law in This Paper. For evaluation formulas of the constitutive law for concrete elements reinforced with $\mathrm{CF}$, the Nakatsuka model is advantageous because it can accommodate both a monotonically increasing model and a maxima model. But, it does not take into account the variation in confinement effect due to changes in chamfer radius of section corners (i.e., the impact of effective confinement area $A_{\mathrm{e}}$ ) in rectangular sections. Moreover, it does 
not consider rectangular cross sections. Authors aim to expand the scope of the Nakatsuka model in this paper.

First, authors set the cross-sectional shape factors $C$ in equations (2), (4), (5), (7), (8), and (9) as functions of the effective confinement area ratio $\alpha_{e}$ instead of fixed values. The previous Nakatsuka's work [13] used $\phi 150 \times 300 \mathrm{~mm}$ round specimens and $150 \times 150 \times 300 \mathrm{~mm}$ square specimens (with chamfer radius $R$ equal to $30 \mathrm{~mm}$ for all). For round sections, the CF sheet exerts a confinement effect on the entire cross section (i.e., the effective confinement area ratio $\alpha_{e}$ based on equation (1) is equal to 1.00), and the crosssectional shape factors $C$ in the study are all equal to 1.0 (i.e., without correction). For square-sectioned specimens, since the value of the effective confinement area ratio $\alpha_{e}$ fell to 0.75 , the cross-sectional shape factors $C$ take the values given in Section 2.2. Furthermore, since the effect of CF reinforcement is lost in the case when the effective confinement area ratio $\alpha_{e}$ becomes zero, the cross-sectional shape factors $C$ should also be zero. Accordingly, the cross-sectional shape factors $C$ of the Nakatsuka model are extended and defined as follows in this paper:

$$
\begin{aligned}
C_{\sigma B} & =C_{\varepsilon B}=C_{\varepsilon T}=\max \left\{\begin{array}{l}
1.6 \alpha_{e}-0.6, \\
0.8 \alpha_{e},
\end{array}\right. \\
C_{E B T} & =C_{E T R}=\max \left\{\begin{array}{l}
2.4 \alpha_{e}-1.4, \\
0.53 \alpha_{e},
\end{array}\right. \\
C_{\varepsilon R} & =1.33 \alpha_{e} \leq 1.00 .
\end{aligned}
$$

In order to apply to rectangular cross sections, new correction factors are defined as functions of the longitudinal ratio $(d / b)$. These correction factors are defined and derived in the latter part of this paper, and their accuracy is verified against the test results in order to conform with the experimental results given in Section 3.

\section{Uniaxial Compression Tests of the CF- Reinforced Concrete Element}

3.1. Specimen Setup. The test specimens are shown in Table 1, while the material properties of the CF sheet are shown in Table 2. There are five $C$-series test specimens with circular cross sections, seven $S$-series test specimens with square cross sections, and nine $R$-series test specimens with rectangular cross sections for a total of 21 specimens. Figure 4 shows the configuration of rectangular-sectioned specimens.

The $C$ series uses the weight of the CF sheet (five types weighing from $0-600 \mathrm{~g} / \mathrm{m}^{2}$; the $400 \mathrm{~g} / \mathrm{m}^{2}$ and $600 \mathrm{~g} / \mathrm{m}^{2}$ weights are double wrapped $200 \mathrm{~g} / \mathrm{m}^{2}$ and $300 \mathrm{~g} / \mathrm{m}^{2} \mathrm{CF}$ sheets) as the variable, with the aim of re-examining the validity of the Nakatsuka model proposed in a previous Nakatsuka's study [13]. The $S$ series uses the weight of the CF sheet (five types weighing from $0-600 \mathrm{~g} / \mathrm{m}^{2}$, as in the $C$ series), the chamfer radius $R$ of section corners (two types at $15 \mathrm{~mm}$ and $30 \mathrm{~mm}$; the $30 \mathrm{~mm}$ radius test specimen S12-3R has the same cross-sectional shape as a test specimen in the Nakatsuka's previous study), and the height ratio (i.e., ratio
TABLE 1: Test specimens.

\begin{tabular}{lcccccc}
\hline & \multicolumn{3}{c}{ Dimension of concrete } & \multicolumn{2}{c}{ CF sheet } \\
Specimen & $b(\mathrm{~mm})$ & $d(\mathrm{~mm})$ & $h(\mathrm{~mm})$ & $R(\mathrm{~mm})$ & $\begin{array}{c}\rho_{f} \\
\left(\mathrm{~g} / \mathrm{m}^{2}\right)\end{array}$ & $p_{f}(\%)$ \\
\hline C12-0 & \multicolumn{2}{c}{$\phi 150$} & 300 & & - & - \\
$\mathrm{C} 12-2$ & \multicolumn{1}{c}{$\phi 150$} & 300 & & 200 & 0.148 \\
$\mathrm{C} 12-3$ & \multicolumn{2}{c}{$\phi 150$} & 300 & - & 300 & 0.223 \\
$\mathrm{C} 12-4$ & \multicolumn{1}{c}{$\phi 150$} & 300 & & 400 & 0.296 \\
$\mathrm{C} 12-6$ & \multicolumn{2}{c}{$\phi 150$} & 300 & & 600 & 0.446 \\
\hline S12-0 & 150 & 150 & 300 & & - & - \\
S12-2 & 150 & 150 & 300 & & 200 & 0.148 \\
S12-3 & 150 & 150 & 300 & 15 & 300 & 0.223 \\
S12-4 & 150 & 150 & 300 & & 400 & 0.296 \\
S12-6 & 150 & 150 & 300 & & 600 & 0.446 \\
S13-3 & 150 & 150 & 450 & & 300 & 0.223 \\
S12-3R & 150 & 150 & 300 & 30 & 300 & 0.223 \\
\hline R22-2 & 150 & 300 & 300 & & 200 & 0.148 \\
R22-3 & 150 & 300 & 300 & & 300 & 0.223 \\
R23-3 & 150 & 300 & 450 & & 300 & 0.223 \\
R32-2 & 100 & 300 & 200 & & 200 & 0.222 \\
R32-3 & 100 & 300 & 200 & 15 & 300 & 0.334 \\
R33-3 & 100 & 300 & 300 & & 300 & 0.334 \\
R42-2 & 100 & 400 & 200 & & 200 & 0.222 \\
R42-3 & 100 & 400 & 200 & & 300 & 0.334 \\
R43-3 & 100 & 400 & 300 & & 300 & 0.334 \\
\hline
\end{tabular}

of height $h$ to the short side $b$; two types at 2 and 3 in this paper) as variables, with the aim of verifying the validity of cross-sectional shape factors $C$ that depend on the effective confinement area ratio $\alpha_{e}$ (equations (10)-(12)). The $R$ series uses the longitudinal ratio $d / b$ (four types from $1-4$ ), the weight of the CF sheet (two types at $200 \mathrm{~g} / \mathrm{m}^{2}$ and $300 \mathrm{~g} / \mathrm{m}^{2}$ ), and the height ratio (two types at 2 and 3 ) as variables, with the aim of studying applicability to rectangular cross sections. The maximum longitudinal ratio is set to 4 based on the fact that the distance between the neutral axis of the wall base cross section subjected to flexural compression and the wall end on the compression side is 3 to 4 times the wall thickness in static loading tests of columnless walls reinforced with CF in a previous study.

For the names of test specimens, the second character indicates the value of the longitudinal ratio $d / b$, the third character indicates the value of the height ratio $h / b$, and the fourth character indicates the CF sheet weight $\rho_{f}$ (0: no reinforcement, $2: 200 \mathrm{~g} / \mathrm{m}^{2}, 3: 300 \mathrm{~g} / \mathrm{m}^{2}, 4: 400 \mathrm{~g} / \mathrm{m}^{2}$, and 6 : $600 \mathrm{~g} / \mathrm{m}^{2}$ ). Note that, in Table $1, p_{f}$ is the reinforcement ratio of the CF sheet, which is the ratio of the sheet thickness $t$ over the short side $b$ of the concrete cross section. The fifth character indicates the chamfer radius (no letter: $R=15 \mathrm{~mm}$, R: $30 \mathrm{~mm})$.

3.2. Loading and Measuring System. The loading used is the monotonic uniaxial compression system. The displacement of the axial direction is measured from four displacement transducers. These are placed at every $90^{\circ}$ circumferential direction of the specimen cross section. The axial strain of the specimen is defined as the average of four displacement transducers. 
Table 2: Properties of the carbon fiber sheet.

\begin{tabular}{lccccc}
\hline$\rho_{f}\left(\mathrm{~g} / \mathrm{m}^{2}\right)$ & $E_{f}\left(\mathrm{~N} / \mathrm{mm}^{2}\right)$ & $f_{f}\left(\mathrm{~N} / \mathrm{mm}^{2}\right)$ & $\varepsilon_{f r}(\%)$ & Specific weight $\left(\times 10^{6} \mathrm{~g} / \mathrm{m}^{2}\right)$ & 1.80 \\
200 & 251,000 & 4,445 & 1.72 & 1.80 & 0.111 \\
300 & 251,000 & 4,728 & 1.88 & 1.80 \\
\hline
\end{tabular}

$f_{f}$ : tensile strength of the carbon fiber sheet.

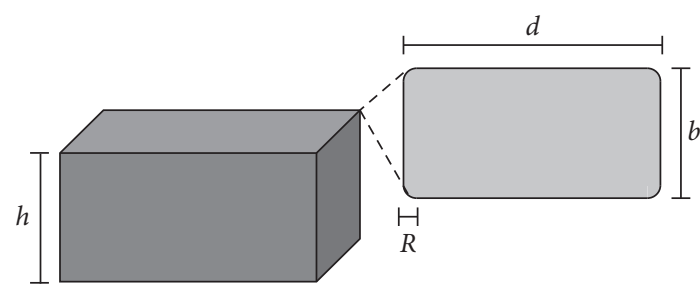

Figure 4: Dimensions of the test specimen with rectangular cross section.

3.3. Test Results of C-Series Test Specimens. Figure 5 shows the results of the monotonic uniaxial compression tests on the $C$ series. In the figure, the vertical axis is the stress $\sigma$ and the horizontal axis is the strain $\varepsilon$. The graph in Figure 5(a) shows the comparison of test results for the five $C$-series test specimens, while graphs $5(\mathrm{~b})-5(\mathrm{e})$ show the comparison of test results for each of the four test specimens with $\mathrm{CF}$ reinforcement and the Nakatsuka model [13]. For round specimens with effective confinement area ratio $\alpha_{e}$ of 1.0, all of the stress-strain relationships are described by the monotonically increasing model (see Figure 3 ).

The failure mode (ultimate strain $\varepsilon_{R}$ ) of specimens was determined by the rupture behavior of CF sheets. Comparing on the basis of the weight of the $\mathrm{CF}$ sheet, the maximum bearing strength and ultimate strain $\varepsilon_{R}$ of the concrete element significantly improved with higher $\mathrm{CF}$ sheet weight. Comparing the test results of the CF-reinforced test specimens and the Nakatsuka model shown in Figures 5(b)-5(e), the test values and the evaluation model are generally in good agreement. Based on these results, it can be said that the Nakatsuka model can accurately estimate the stress-strain relationship of CF-reinforced concrete elements on the condition that the effective confinement area ratio $\alpha_{e}$ is 1.0 .

3.4. Test Results of S-Series Test Specimens. Figure 6 shows the results of the monotonic uniaxial compression tests on the $S$ series. Figure 6(a) shows the comparison of different CF sheet weights, while Figure 6(b) compares different chamfer radii $R$ and Figure 6(c) compares different height ratios $h / b$. Note that, for test specimen S13-3 with a height ratio of $h /$ $b=3$, the test results are based on the gauge length of the specific section. For the rectangular specimens in this paper, all of the stress-strain relationships are described by the maxima model (see Figure 3).

The failure mode of specimens was determined by the rupture behavior of $\mathrm{CF}$ sheets as well as the $C$ series. Comparing on the basis of the weight of the CF sheet, the plastic deformation capacity of the concrete element rose with higher weight of the CF sheet, with a particularly pronounced change in the ultimate strain $\varepsilon_{R}$. For the compressive strength $\sigma_{B}$, a tendency for the strength to increase with higher CF sheet weight can also be seen, although the change is not as extreme as in the ultimate strain $\varepsilon_{R}$. Comparing on the basis of chamfer radius shown in Figure 6(b), the strength reduction after reaching compressive strength $\sigma_{B}$ of test specimen S12-3R (provided with an equivalent effective confinement area ratio $\alpha_{e}=0.75$ as a test specimen in a previous Nakatsuka's study [13]) is comparatively more gradual than that of test specimen S12-3 $\left(\alpha_{e}=0.57\right)$. Comparing on the basis of height ratio $h / b$ in Figure 6(c), test specimens S12-3 and S13-3 show nearly the same stress-strain relationship. In this paper, authors argue that the effect of the height ratio $h / b$ on the stress-strain relationship of CF-reinforced concrete elements is small.

Table 3 presents the six components that define the constitutive law of the Nakatsuka model: $\sigma_{\mathrm{B}}, \varepsilon_{\mathrm{B}}, E B T, \varepsilon_{\mathrm{T}}$, $E T R$, and $\varepsilon R$, for the 15 rectangular specimens reinforced with CF. The experimental values (Exp.) in the table are the values that identify the six components above, taken from the stress-strain relationships obtained by experiments according to the previous study. The estimation values (Est.) in the table are the values obtained by evaluating the CFreinforced test specimens in this paper based on equations (1) through (12) (i.e., considering the effect of effective confinement area ratio $\alpha_{e}$ ). For $F_{0}$, the compressive strength of test specimen S12-0 which equals $38.46 \mathrm{MPa}$ is used, while for $\varepsilon_{0}$, the strain for the same compressive strength which equals 0.0024 is used.

Figure 7 shows the comparison of the test results for the six $S$-series test specimens with CF reinforcement and the evaluation results based on the constitutive law. The solid lines in the figure show the experimental results, the short dashed lines show the Nakatsuka model (i.e., without considering the effect of effective confinement area ratio $\alpha_{e}$ ), and the dashed-dotted lines show the constitutive law proposed in this paper (equations (1)-(12)). The Nakatsuka model tends to overestimate the experimental values in the second region and thereafter. This may be attributed to the fact that the Nakatsuka model does not consider the effect of the effective confinement area ratio $\alpha_{e}$, which is linked to the chamfer radius $R$. In general, the constitutive law proposed in this paper may be considered as capable of reproducing the experimental results well. Note that, for test specimen S12-6, in which the weight of the CF sheet is extremely large, although the estimation of the stiffness in the third region $E_{T R}$ is too large, the ultimate strain $\varepsilon_{R}$ is almost the same as the experimental value.

The aforementioned results suggest that the constitutive law proposed in this paper (i.e., expanded formulas of the Nakatsuka model), which can take into account the effect of the effective confinement area ratio $\alpha_{e}$, can generally 


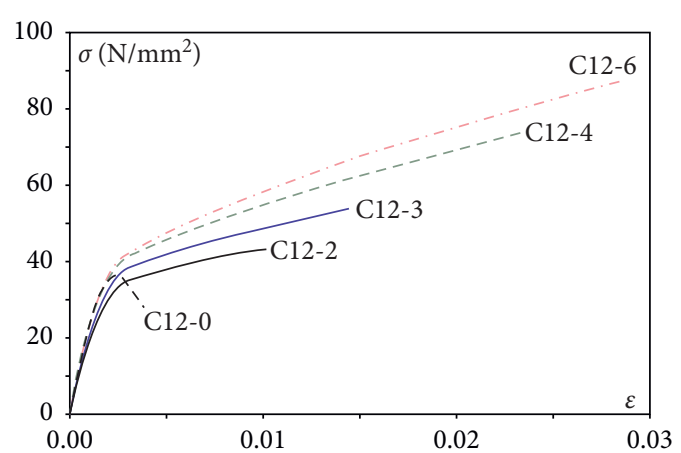

(a)

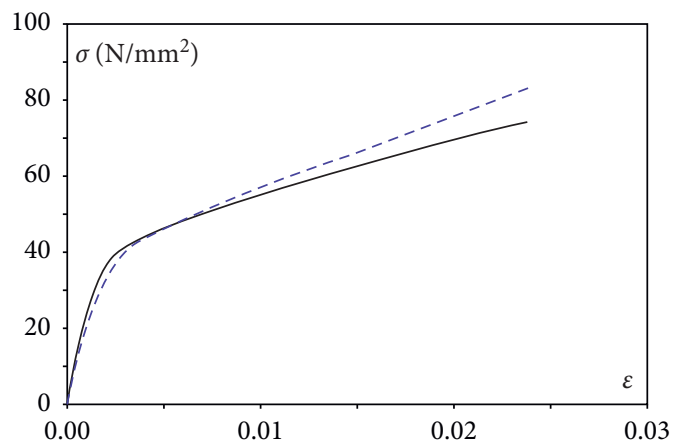

(d)

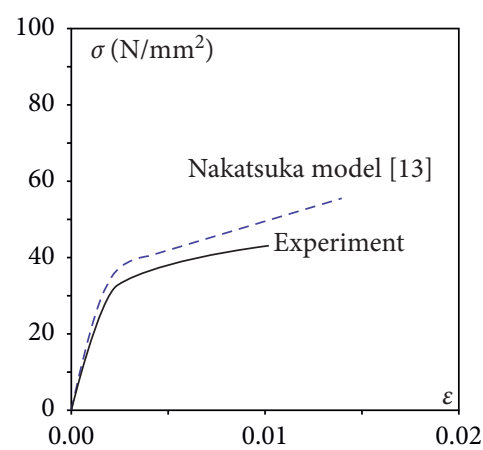

(b)

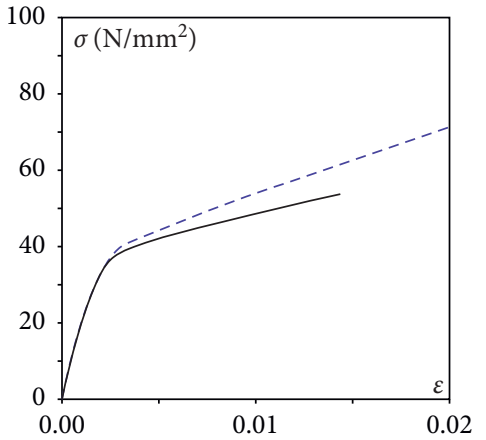

(c)

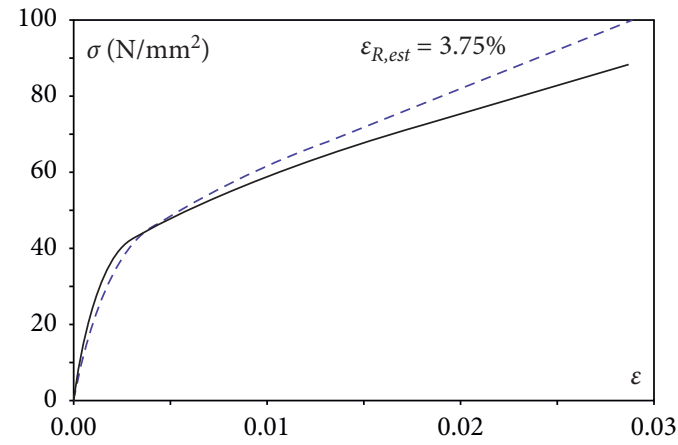

(e)

Figure 5: Test results for the $C$-series test specimens and the Nakatsuka model. (a) Comparing on the basis of CF sheet weight. (b) Comparing test results and Nakatsuka model of specimen C12-2. (c) C12-3. (d) C12-4. (e) C12-6.

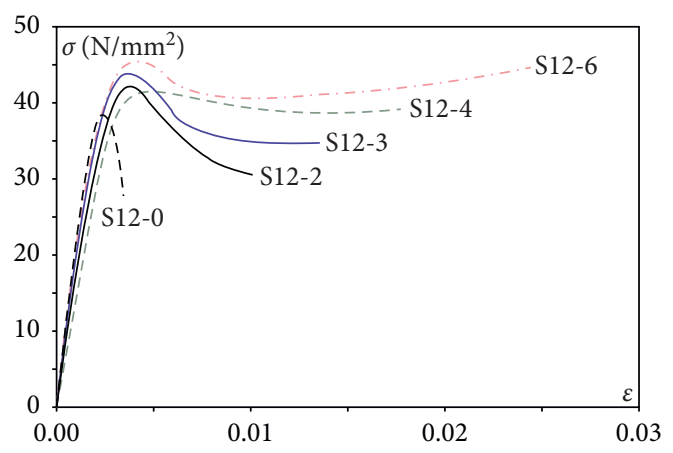

(a)

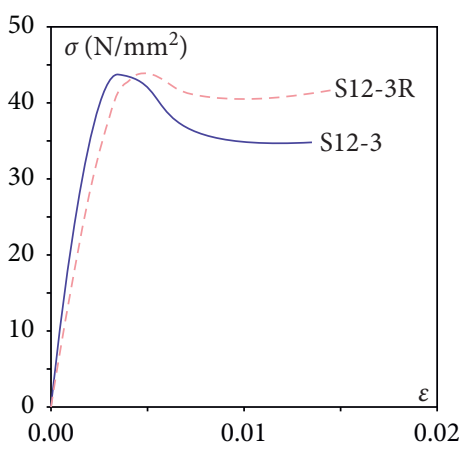

(b)

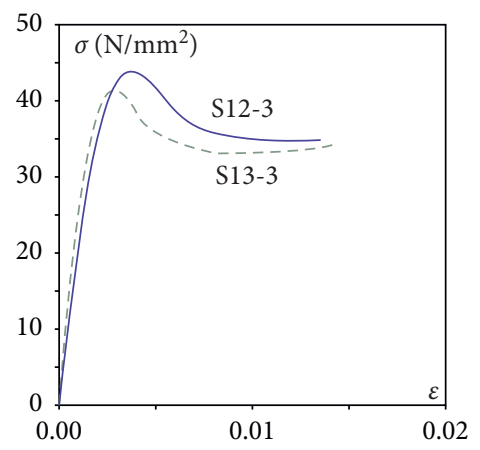

(c)

Figure 6: Comparing the test results for the $C$-series specimens. (a) CF sheet weight. (b) Different chamfer radii $R$. (c) Different height ratios $h / b$.

estimate the behavior of square concrete elements reinforced with CF well. The accuracy of the estimation is particularly good when the weight of the CF sheet is $300 \mathrm{~g} / \mathrm{m}^{2}$ or less.

3.5. Test Results of R-Series Test Specimens. For the $R$-series test specimens, the comparison of the six component values of the constitutive law identified from experimental results and the estimation values based on equations (1)-(12) (without considering the effect of longitudinal ratio $d / b$ ) is shown in Table 3. First, for the compressive strength $\sigma_{B}$, the estimation values overestimate the experimental values for all test specimens in which the longitudinal ratio $d / b$ is 2 or more. On the contrary, the strain at point of constant sloping $\varepsilon_{T}$ and ultimate strain $\varepsilon_{R}$ tend to be underestimated. The ultimate strain $\varepsilon_{R}$ relative to the failure mode is defined as the point when rupture occurs in the CF sheet. Figure 8 shows examples of the ultimate state of the test specimens due to CF sheet rupture. All of the test specimens with a longitudinal ratio $d / b$ of 2 or more had concrete on the long side bulging out of plane at the final stage. This behavior is quite pronounced in the R42-3 test specimen shown in Figure $8(\mathrm{~d})$. Figure 9 shows the failure mode of rectangle specimen R42-3. The rupture of the CF sheet occurred at the 
TABle 3: Comparison of the test results and the constitutive law using the Nakatsuka model with six components.

\begin{tabular}{|c|c|c|c|c|c|c|c|c|c|c|c|c|c|c|c|c|c|c|}
\hline \multirow{2}{*}{ Specimen } & \multicolumn{3}{|c|}{$\sigma_{B}(\mathrm{Mpa})$} & \multicolumn{3}{|c|}{$\varepsilon_{B} \times 10^{-2}$} & \multicolumn{3}{|c|}{$E_{B T}(\mathrm{Mpa})$} & \multicolumn{3}{|c|}{$\varepsilon_{T} \times 10^{-2}$} & \multicolumn{3}{|c|}{$E_{T R}(\mathrm{MPa})$} & \multicolumn{3}{|c|}{$\varepsilon_{R} \times 10^{-2}$} \\
\hline & Exp. & Est. & $\frac{\text { Est. }}{\text { Exp. }}$ & Exp. & Est. & $\frac{\text { Est. }}{\text { Exp. }}$ & Exp. & Est. & $\frac{\text { Est. }}{\text { Exp. }}$ & Exp. & Est. & $\frac{\text { Est. }}{\text { Exp. }}$ & Exp. & Est. & $\frac{\text { Est. }}{\text { Exp. }}$ & Exp. & Est. & $\frac{\text { Est. }}{\text { Exp. }}$ \\
\hline S12-2 & 42.21 & 39.92 & 0.95 & 0.38 & 0.26 & 0.69 & -2760 & -2302 & 0.83 & 0.65 & 0.54 & 0.83 & -1304 & 74 & -0.06 & 1.06 & 1.01 & 0.95 \\
\hline & & & 0.93 & 37 & 0.27 & 0.73 & & & 0.42 & 0.73 & 0.57 & 0.78 & & & -2.58 & 1.35 & & 1.07 \\
\hline & 89 & & 0.99 & 0.50 & 0.28 & 0.57 & -591 & 33 & -0.06 & 0.78 & 0.60 & 0.76 & -92 & 991 & -10.7 & 1.79 & 1.66 & 0.93 \\
\hline $2-6$ & .55 & 42.85 & 0.94 & 0.42 & 0.31 & 0.73 & -1005 & 1143 & -1.14 & 0.91 & 0.64 & 0.71 & 261 & 1428 & 5.47 & 2.45 & 2.53 & 1.03 \\
\hline & 46 & & 0.98 & & & 0.92 & -2836 & & & & & 1.19 & -235 & & -2.71 & 1.44 & & 1.01 \\
\hline & 3.93 & 41.36 & 0.94 & 0.49 & 0.28 & 0.58 & -985 & 10 & -0.01 & 0.80 & 0.59 & 0.74 & 120 & 982 & 8.21 & 1.44 & 1.79 & 1.24 \\
\hline & & & & & & & & & & & & & & & & 22 & & 0.79 \\
\hline & 36.85 & 40.44 & 1.10 & 0.42 & 0.27 & 0.64 & -2630 & -1214 & 0.46 & 1.07 & 0.56 & 0.53 & -198 & 502 & -2.53 & 1.91 & 1.35 & 0.71 \\
\hline R23-3 & 36.71 & 40.44 & 1.10 & 0.40 & 0.27 & 0.67 & -3349 & -1214 & 0.36 & 0.82 & 0.56 & 0.68 & -453 & 502 & -1.11 & 1.09 & 1.35 & 1.23 \\
\hline & & & 1.02 & 0.34 & 0.27 & 0.79 & -2259 & -914 & & 1.01 & & 0.56 & & & -0.57 & 2.35 & & 0.56 \\
\hline & & & 1.07 & & & 0.54 & -2376 & & -0 . & & & & & & -1.92 & 2.16 & & 0.91 \\
\hline R33-3 & 39.87 & 41.72 & 1.05 & 0.32 & 0.29 & 0.90 & -2866 & 356 & -0.12 & 1.01 & 0.61 & 0.6 & & 1118 & -8.3 & 2.15 & 1.97 & 0.92 \\
\hline & & & 1.01 & & & 0.73 & & -1002 & & & & & & & -0.78 & 1.94 & & 0.67 \\
\hline R42-3 & 38.59 & 41.64 & 1.08 & 0.50 & 0.29 & 0.58 & -1391 & 281 & -0.20 & 2.00 & 0.60 & 0.30 & -127 & 1089 & -8.58 & 3.07 & 1.93 & 0.63 \\
\hline R43-3 & 32.60 & 41.64 & 1.28 & 0.39 & 0.29 & 0.74 & -2249 & 281 & -0.12 & 1.02 & 0.60 & 0.59 & -370 & 1089 & -2.94 & 1.87 & 1.93 & 1.04 \\
\hline
\end{tabular}

corner of the specimen. In the ultimate state, both surfaces of the long side swelled to the out of plane. Along with this behavior, large tension was acting on the long side CF sheets. This implies that the link between the longitudinal ratio $d / b$ and magnitude of ultimate strain is related to this failure behavior.

The aforementioned results suggest that, for CF-reinforced concrete elements with rectangular sections, although compressive strength $\sigma_{B}$ fell compared to square sections, plastic deformation capacity tends to improve.

\section{Constitutive Law for Rectangular Cross Sections}

4.1. Discussion of Test Results. With regard to the tendency for compressive strength $\sigma_{B}$ to fall with increasing longitudinal ratio $d / b$, a similar behavior has been observed for plain concrete without CF reinforcement. Yamamoto and Koike [25] carried out a number of uniaxial compression tests on rectangular concrete element specimens with longitudinal ratios $d / b$ less than 6 and gave the following equation for the reduction factor $\alpha_{\sigma B}$ of compressive strength $\sigma_{B}$ estimation according to longitudinal ratio $d / b$ :

$$
\alpha_{\sigma B}=\left(\frac{d}{b}\right)^{-0.1}
$$

Based on this, authors applied the following equation in lieu of equation (2) as the evaluation formula for compressive strength $\sigma_{B}$ of CF-reinforced concrete elements in this paper:

$$
\sigma_{B}=\alpha_{\sigma B}\left[F_{0}+4 p_{f} E_{f} \varepsilon_{f B} C_{\sigma B}\right]
$$

Moreover, authors evaluated the strain at compressive strength $\sigma_{B}$ using the following equation, considering that, to a certain extent, a proportional relationship with compressive strength $\sigma_{B}$ exists:

$$
\varepsilon_{B}=\alpha_{\sigma B}\left[\varepsilon_{0}+10 \varepsilon_{0} \frac{p_{f} E_{f} \varepsilon_{f B}}{F_{0}} C_{\varepsilon B}\right] .
$$

It has also been observed that, with respect to the strain at point of constant sloping $\varepsilon_{T}$, which defines the boundary between the second and third regions and was shown to deteriorate in the test specimens and the ultimate strain $\varepsilon_{R}$ of the specimens determined by the CF sheet ruptures, the magnitude of strain tends to increase as the longitudinal ratio $d / b$ becomes larger. In the test results of this study, the experimental values of test specimens with longitudinal ratio $d / b=4$ generally reached about twice the estimation values of equations (1)-(12). In contrast, the estimation values for stiffness in the second region $E_{B T}$ and stiffness in the third region $E_{T R}$ tend to overestimate the experimental values.

Figure 10 shows the ratios of cross-sectional shape factors $C_{E B T}, C_{\varepsilon T}, C_{E T R}$, and $C_{\varepsilon R}$ inversely estimated from experimental values over estimation values from equations (10)-(12) for the four components $E_{B T}, \varepsilon_{T}, E_{T R}$, and $\varepsilon_{R}$ of the $R$-series test specimens. In the figure, the vertical axis is the ratio of experimental over estimation values $C_{\exp } / C_{\text {est }}$ and the horizontal axis is the longitudinal ratio $d / b$. Similar to the previous discussion, the ratio $C_{\exp } / C_{\text {est }}$ tends to fall with increasing longitudinal ratio $d / b$ with respect to $E_{B T}$ in Figure $10(\mathrm{a})$ and $E_{T R}$ in Figure $10(\mathrm{c})$. Conversely, the ratio $C_{\text {exp }} / C_{\text {est }}$ also becomes large as the longitudinal ratio $d / b$ increases for $\varepsilon_{T}$ in Figure 10(b) and $\varepsilon_{R}$ in Figure 10(d). In this paper, authors modified the evaluation formulas for four components: $E_{B T}, \varepsilon_{T}, E_{T R}$, and $\varepsilon_{R}$ from equations (5), (7), (8), and (9) to the following in order to take the longitudinal ratio $d / b$ into account:

$$
E_{B T}=-0.4 E_{0 B T}+\frac{1.4 E_{0 B T}}{\alpha_{E B T} C_{E B T}\left(p_{f} E_{f} / 0.06 F_{0}^{2}\right)+1},
$$

$$
\alpha_{E B T}=-0.2\left(\frac{d}{b}\right)+1.2
$$




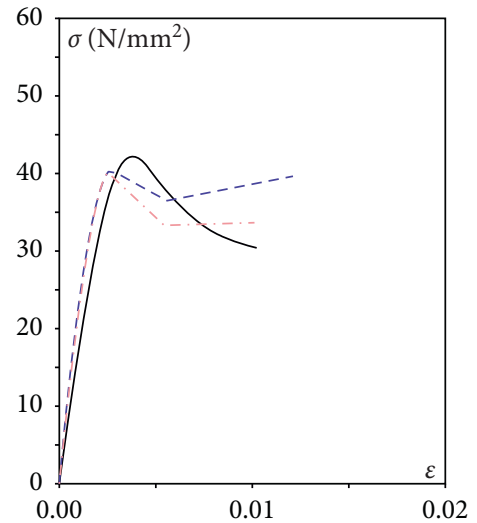

(a)

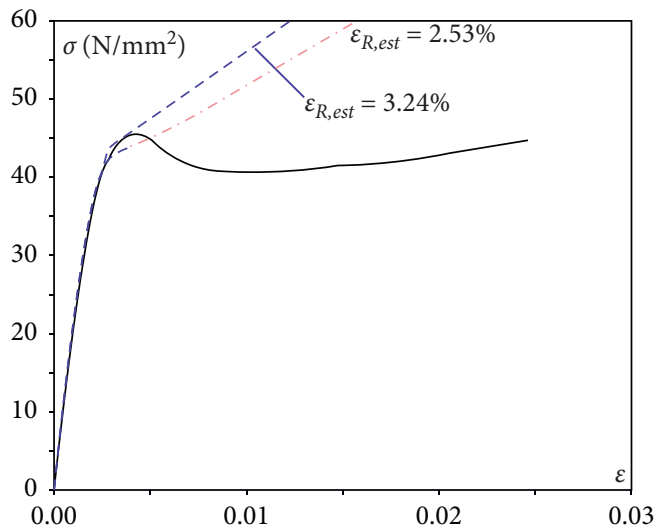

(d)

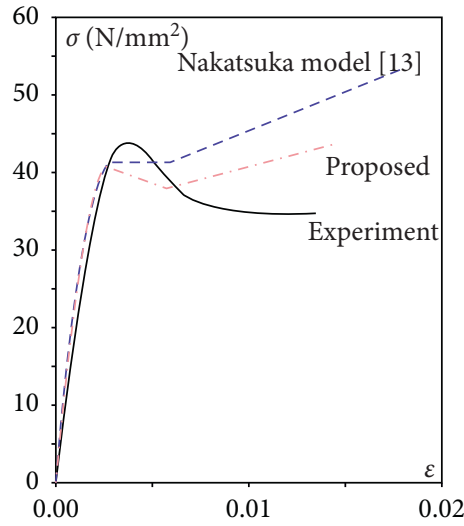

(b)

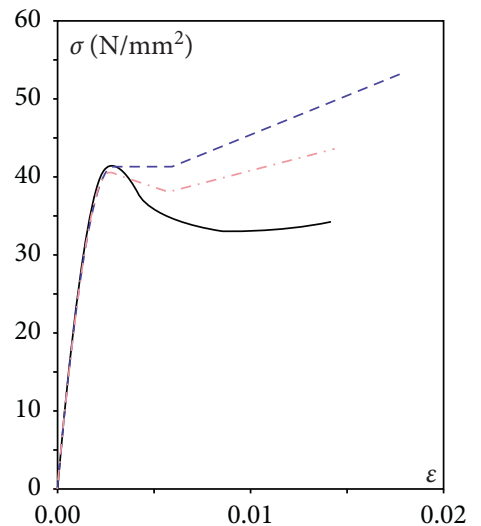

(e)

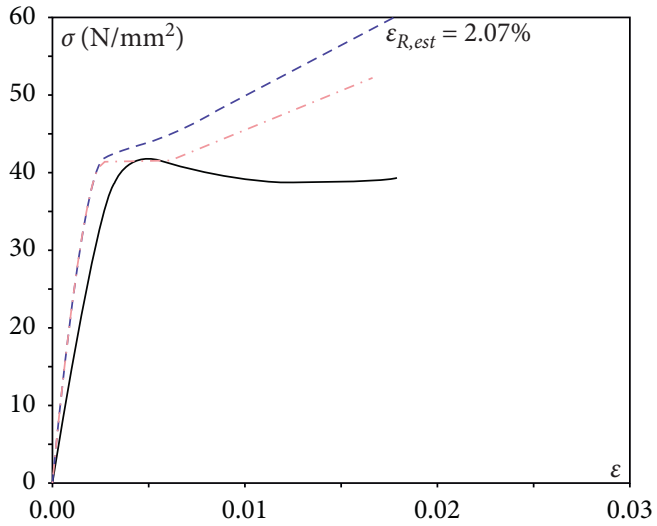

(c)

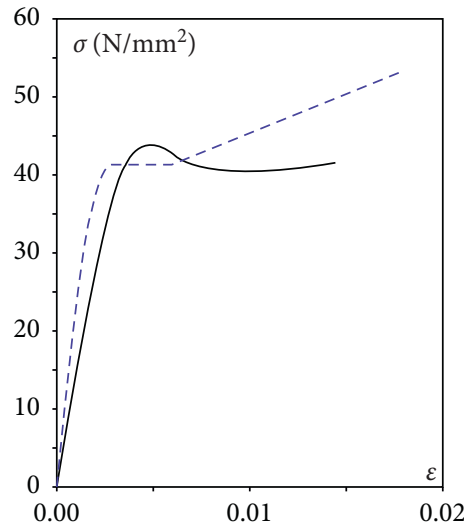

(f)

Figure 7: Test results for the $S$-series test specimens, the Nakatsuka model, and the proposed constitutive law in this paper. (a) S12-2. (b) S12-3. (c) S12-4. (d) S12-6. (e) S13-3. (f) S12-3R.

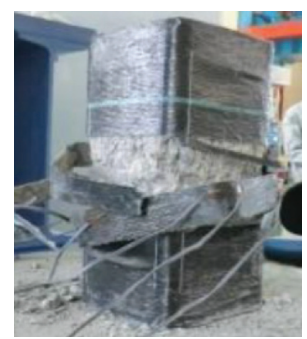

(a)

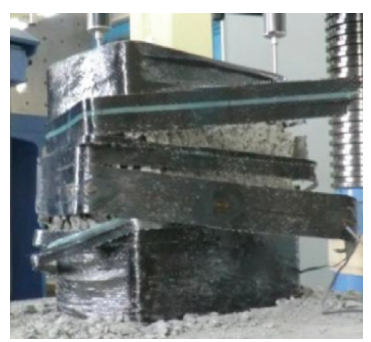

(b)

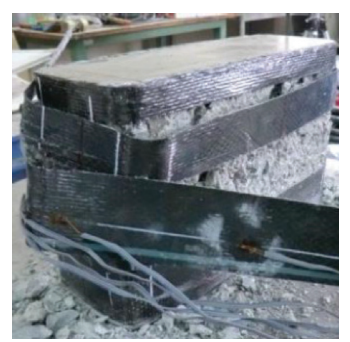

(c)

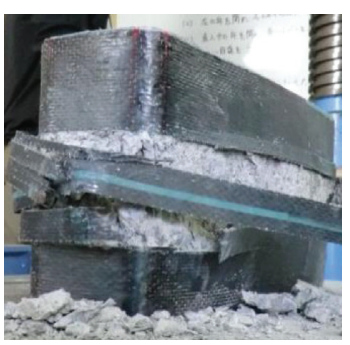

(d)

FIgURE 8: Ultimate state of test specimens. (a) S12-3. (b) R22-3. (c) R32-3. (d) R42-3.

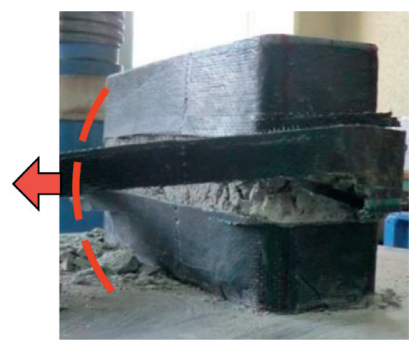

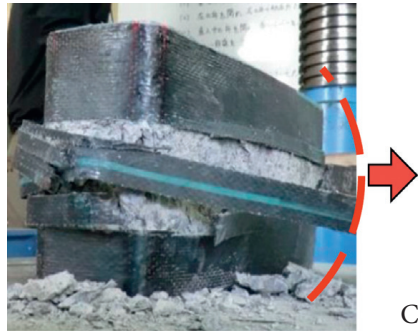

CF sheet rupture

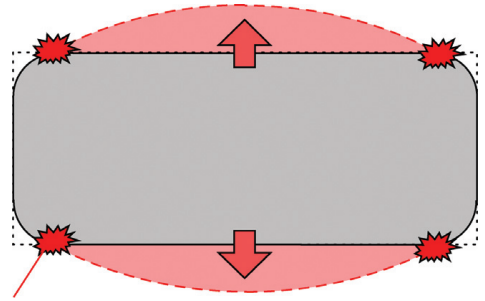

FIgURE 9: Failure mode of rectangle specimen R42-3. 


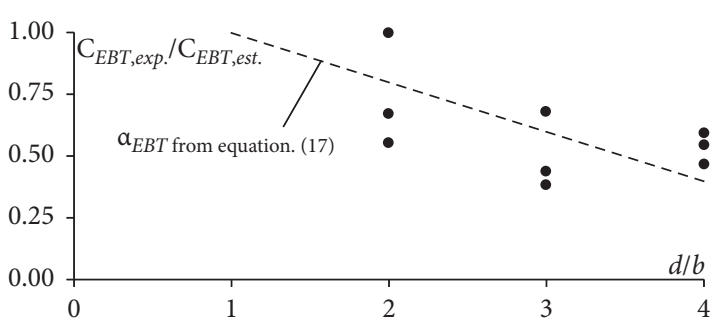

(a)

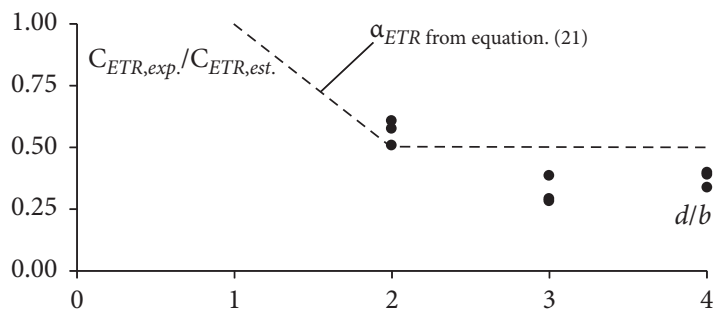

(c)

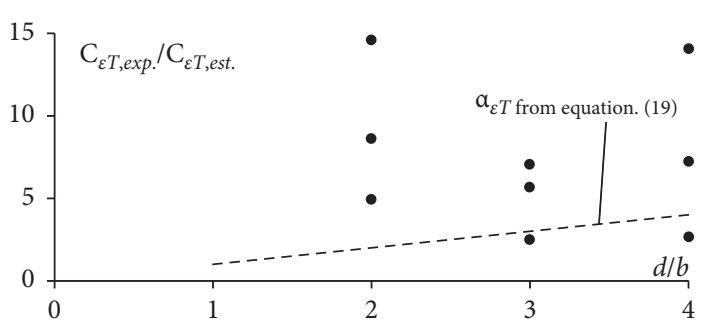

(b)

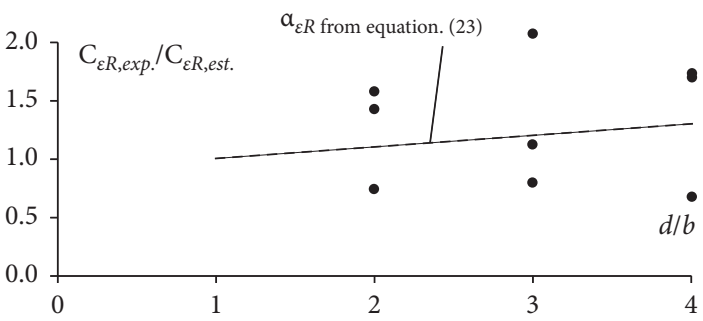

(d)

FiguRE 10: Correction factor for longitudinal ratio of nine $R$-series test specimens. (a) $E_{B T}$ and $\alpha_{E B T}$. (b) $\varepsilon_{T}$ and $\alpha_{\varepsilon T}$. (c) $E_{T R}$ and $\alpha_{E T R}$. (d) $\varepsilon_{R}$ and $\alpha_{\varepsilon R}$.

$$
\begin{gathered}
\varepsilon_{T}=\varepsilon_{0}\left(-0.016 F_{0}+2.7\right) \\
+\varepsilon_{0}\left(0.00001 F_{0}+0.0016\right) \alpha_{\varepsilon T} C_{\varepsilon T} p_{f} E_{f}, \\
E_{T R}=-0.25 E_{0 B T}+\frac{d}{\alpha_{E T R} C_{E T R}\left(p_{f} E_{f} / 0.06 F_{0}^{2}\right)+1}, \\
\alpha_{E T R}=-0.5\left(\frac{d}{b}\right)+1.5 \geq 0.5 \\
\varepsilon_{R}=\varepsilon_{0}\left(20 \varepsilon_{f r}+1.2\right)+\varepsilon_{0}\left(1000 \varepsilon_{f r}-3\right) \alpha_{\varepsilon R} C_{\varepsilon R} \frac{p_{f} E_{f}}{F_{0}^{2}} \\
\alpha_{\varepsilon R}=0.1\left(\frac{d}{b}\right)+0.9 .
\end{gathered}
$$

The dashed lines in Figure 10 indicate the correction factor $\alpha$, which represents the effect of longitudinal ratio $d / b$ based on equations (17), (19), (21), and (23) above. Table 4 presents the error of the proposed equation to the experimental results. For $\alpha_{E B T}, \alpha_{E T R}$, and $\alpha_{\varepsilon R}$, the correction factors given above generally capture the characteristics of the experimental results. For $\alpha_{\varepsilon T}$, the correspondence with the experimental results was not reasonable. The evaluation value from (19) mostly corresponds to the lower limit of the experimental results. At the Nakatsuka model, the strain at the point of constant sloping $\varepsilon_{T}$ is specified as the point at which the tangential slope of an infinitesimal area in the stress-strain relationship becomes nearly constant. However, if the stress-strain relationship is such that the tangential stiffness after reaching compressive strength $\sigma_{B}$ keeps on changing continuously, as in the case of the S12-3R test specimen, then $\varepsilon_{T}$ is overestimated when obtained from experimental results. Therefore, the estimation of $\alpha_{\varepsilon T}$ is set at around the lower limit of experimental results in this paper. When using the lower limit value for $\alpha_{\varepsilon T}$, the stress-strain relationship is underestimated (safe side).

\subsection{Comparison of Test Results and the Proposed Constitutive} Law. Figure 11 shows the comparison of the test results for the nine $R$-series test specimens and the proposed constitutive law estimated from equations (1), (3), (6), and (10) through (23). In the figure, the vertical axis is the stress $\sigma$, and the horizontal axis is the strain $\varepsilon$. The solid lines in the figure show the experimental results, the short dashed lines show the Nakatsuka model (i.e., without considering the effects of both effective confinement area ratio $\alpha_{e}$ and longitudinal ratio $d / b$ ), and the dashed-dotted lines show the constitutive law proposed in this paper (i.e., considering the effects of both effective confinement area ratio $\alpha_{e}$ and longitudinal ratio $d / b$ ). Similar to the $S$-series test specimens, the Nakatsuka model greatly overestimates the experimental values in the second region and thereafter. On the contrary, the evaluation formulas for the constitutive law proposed in this paper are generally able to trace the progress of experimental results regardless of the longitudinal ratio $d / b$. However, for some specimens, the initial stiffness of the proposed model is stiffer than the experimental results as shown in Figure 11. The evaluation of initial stiffness that measures infinitesimal displacement is very sensitive and is always associated with errors and uncertainties. In the future, the parametric study and/or the evaluation of dispersion about initial stiffness range is essential.

For the 15 test specimens of square and rectangular cross sections with CF reinforcement in this study, the 
Table 4: Properties of the carbon fiber sheet.

\begin{tabular}{lcccc}
\hline & $\alpha_{E B T}$ & $\alpha_{\varepsilon T}$ & $\alpha_{E T R}$ & $\alpha_{\varepsilon R}$ \\
\hline Average (exp. result/proposed method) & 1.03 & 2.79 & 0.84 & 1.10 \\
Standard deviation of error & 0.28 & 1.83 & 0.21 & 0.37 \\
\hline
\end{tabular}

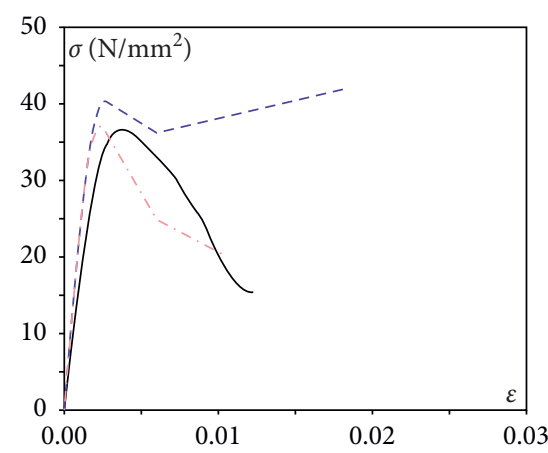

(a)

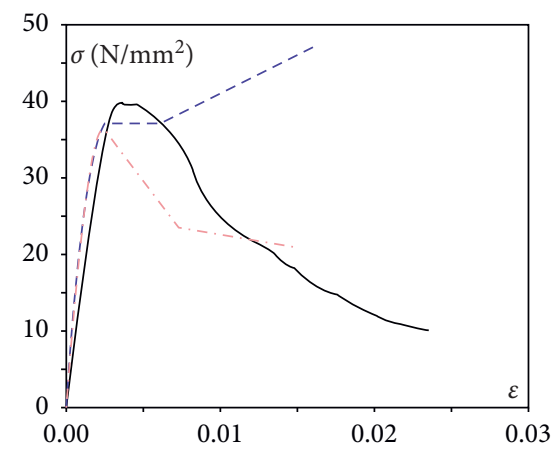

(d)

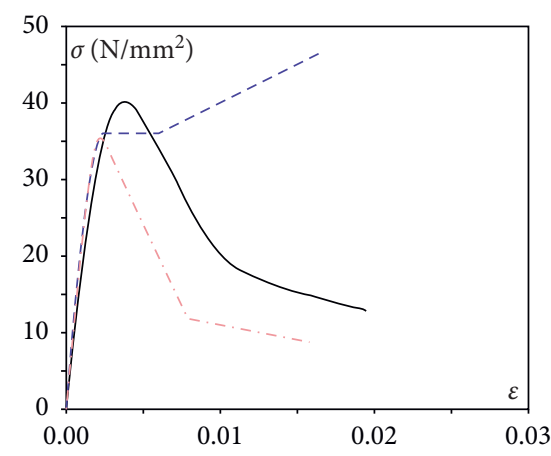

(g)

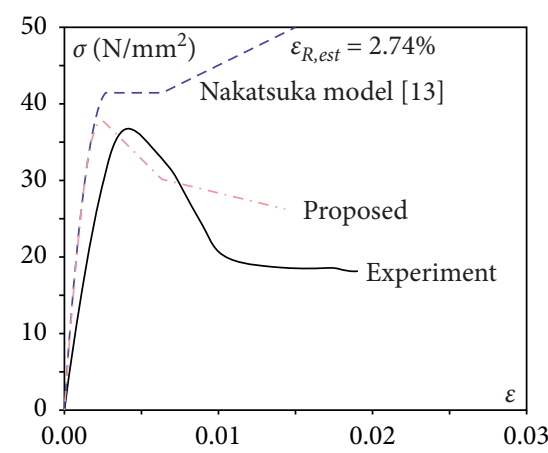

(b)

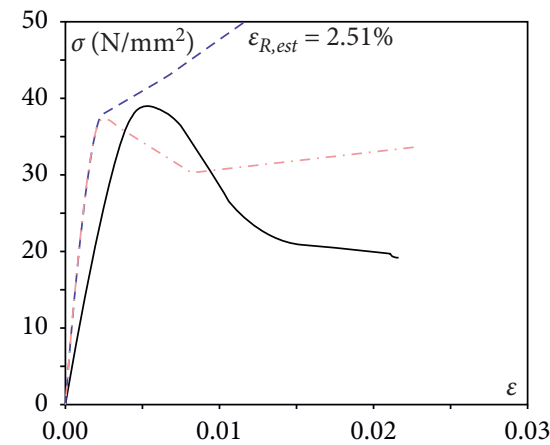

(e)

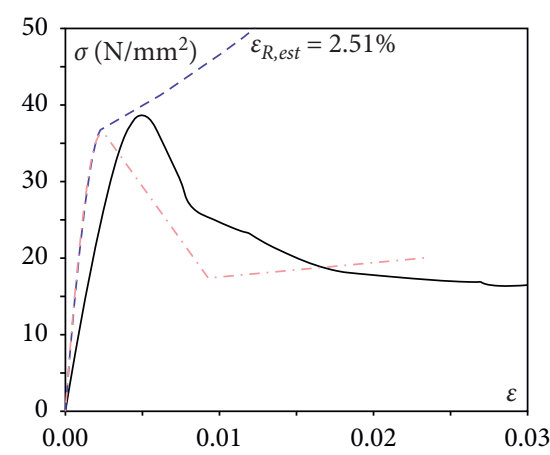

(h)

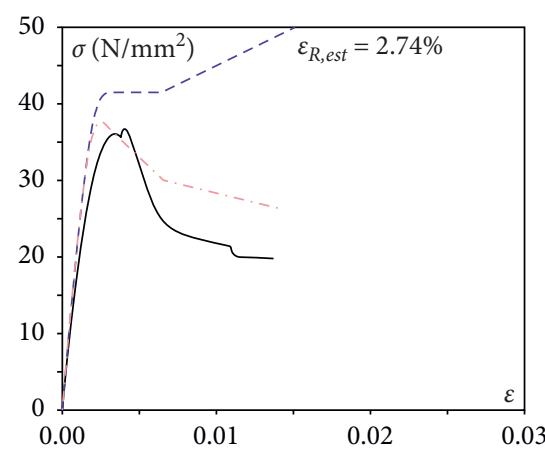

(c)

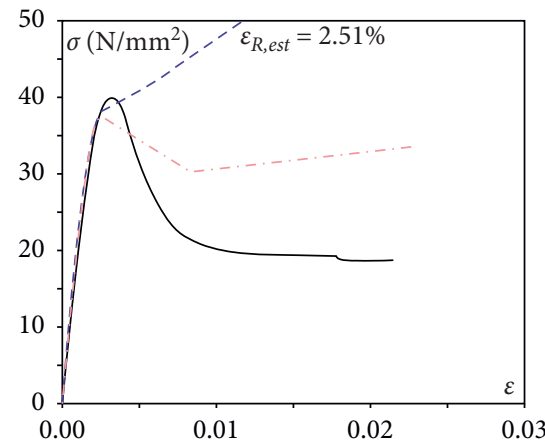

(f)

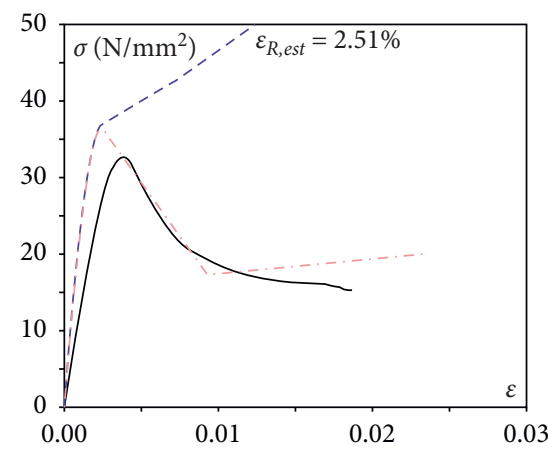

(i)

Figure 11: Test results for the $R$-series test specimens, the Nakatsuka model, and the proposed constitutive law in this paper. (a) R22-2. (b) R22-3. (c) R23-3. (d) R32-2. (e) R32-3. (f) R33-3. (g) R42-2. (h) R42-3. (i) R43-3.

energy consumed by the test specimens until reaching the ultimate state was in the range of $60 \%$ to $148 \%$ of the proposed evaluation formulas in this paper, with an average of $111 \%$ and standard deviation of $27.2 \%$. If this is limited to the $R$-series test specimens with rectangular cross sections, the average is $104 \%$ and standard deviation is $30.8 \%$. All of the above results show that the evaluation formulas for the constitutive law of CF-reinforced concrete elements proposed in this paper can generally estimate the stress-strain relationship, even for rectangular cross sections with widely different lengths on the long and short sides.

\section{Conclusions}

Monotonic uniaxial compression tests were performed on 21 specimens of concrete elements reinforced by wrapping with carbon fiber sheets. The following are our findings within the scope of the specifications of specimens used in the tests (specimen dimensions and CF sheet weight): 
(1) As the aspect ratio of the concrete section increases, the compressive strength decreases, while on the contrary, the ultimate strain determined by the rupture of the carbon fiber sheet increases and ductility capacity improves.

(2) For the experiments in this study, there were no changes observed in the stress-strain relationships of concrete elements reinforced with the carbon fiber sheet as the ratio of height in the direction of axial compression of the element over the short side of the cross section changes.

(3) For rectangular cross sections, the effective confinement area of the CF sheet changes depending on the chamfer radius of section corners. In this paper, authors expanded a previously suggested constitutive law by Nakatsuka et al. [13] and derived evaluation formulas as functions of the effective confinement area ratio for the concrete elements under study. The proposed formulas are generally able to estimate the behavior of concrete elements reinforced with carbon fiber with good accuracy, and the accuracy of the estimation is particularly high when the weight of the sheet is $300 \mathrm{~g} / \mathrm{m}^{2}$ or less.

(4) In order to apply to rectangular cross sections with widely different lengths on the long and short sides, authors proposed correction factors for the constitutive law evaluation formulas as functions of the cross-sectional aspect ratio. Taking these correction factors into account, the formulas proposed in this paper are able to trace the experimental results well, while the energy consumed by the concrete element until the carbon fiber sheet ruptures is generally reproduced.

As described above, the CF sheet has the ability to improve the seismic performance of rectangular cross-section concrete such as a structural wall member, and it is possible to evaluate the effect of retrofitting. These research results can contribute to the improvement of resilience and sustainability of the building structure through retrofit of aging concrete.

The experimental test results about the concrete material are associated with errors and uncertainties. In the future, the evaluation of dispersion (e.g., errors and uncertainties) is essential. Authors will apply a parametric study using the FEM model in the next step.

\section{Data Availability}

The experimental data (stress-strain relationship) used to support the findings of this study are available from the corresponding author upon request.

\section{Conflicts of Interest}

The authors declare that they have no conflicts of interest.

\section{Acknowledgments}

The authors would like to acknowledge the contribution of Toray Industries, Inc., by providing materials and technical guidance during the making of specimens. The material of the test specimens was provided free by the company. Also, the authors are also grateful to Mr. Takashi Sakai, Mr. Kenta Suzuki, Mr. Yuki Kanazawa, and Mr. Kazuhito Tachibana for their valuable assistance throughout this project.

\section{References}

[1] A. Nanni, "Concrete repair with externally bonded FRP reinforcement," Concrete International, vol. 17, no. 6, pp. 22-26, 1995.

[2] H. Toutanji, "Stress-strain characteristics of concrete columns externally confined with advanced fiber composite sheets," ACI Materials Journal, vol. 96, no. 3, pp. 397-404, 1999.

[3] A. M. Vasumathi, K. Rajkumar, and G. G. Prabhu, "Compressive behaviour of RC column with fibre reinforced concrete confined by CFRP strips," Advances in Materials Science and Engineering, vol. 2014, Article ID 601915, 10 pages, 2014.

[4] J. R. Murugadoss, B. J. Lee, J. W. Bang, G. G. Prabhu, and Y. Y. Kim, "Performance analysis of CFRP composite strips confined RC columns under axial compression," Advances in Materials Science and Engineering, vol. 2015, Article ID 170295, 18 pages, 2015.

[5] L. D. Lorenzis and R. Tepfers, "Comparative study of models on confinement of concrete cylinders with fiber-reinforced polymer composites," Journal of Composites for Construction, ASCE, vol. 7, no. 3, pp. 219-237, 2003.

[6] S. A. Carey and K. A. Harries, "Axial behavior and modeling of small-, medium-, and large-scale circular sections confined with CFRP jackets," ACI Structural Journal, vol. 102, no. 4, pp. 596-604, 2005.

[7] N. Zhuang, H. Dong, D. Chen, and Y. Ma, "Experimental study of aged and seriously damaged RC beams strengthened using CFRP composites," Advances in Materials Science and Engineering, vol. 2018, Article ID 6260724, 9 pages, 2018.

[8] J. Y. Lee, H. O. Shin, K. H. Min, and Y. S. Yoon, "Flexural assessment of blast-damaged RC beams retrofitted with CFRP sheet and steel fiber," International Journal of Polymer Science, vol. 2018, Article ID 2036436, 9 pages, 2018.

[9] E. Ercan, B. Arisoy, and O. B. Ertem, "Experimental assessment of RC beam-column connections with internal and external strengthening techniques," Advances in Civil Engineering, vol. 2019, Article ID 2828353, 12 pages, 2019.

[10] S. Ghods, A. Kheyroddin, M. Nazeryan, S. M. Mirtaheri, and M. Gholhaki, "Nonlinear behavior of connections in RCS frames with bracing and steel plate shear wall," Steel and Composite Structures, vol. 22, no. 4, pp. 915-935, 2016.

[11] T. Matsui, T. Saito, and R. Reyna, "Basic study on reinforced concrete shear walls without boundary columns retrofitted by carbon fiber sheets," Journal of Disaster Research, vol. 9, no. 6, pp. 1008-1014, 2014.

[12] K. Suzuki, K. Hayashi, and T. Saito, "Study on the material properties of rectangular concrete reinforcing carbon fiber sheet and evaluation of deformation performance of RC reinforced wall," Proceedings of the Japan Concrete Institute, vol. 38, pp. 433-438, 2016, in Japanese.

[13] T. Nakatsuka, K. Komure, and K. Tagaki, "Stress-strain characteristics of confined concrete with carbon fiber sheet," 
Concrete Research and Technology, vol. 9, no. 2, pp. 65-78, 1998, in Japanese.

[14] S. Pessiki, K. A. Harries, J. Kestner, R. Sause, and J. M. Ricles, "The axial behavior of concrete confined with fiber reinforced composite jackets," Journal of Composites in Construction, ASCE, vol. 5, no. 4, pp. 237-245, 2001.

[15] L. Lam and J. G. Teng, "Design-oriented stress strain model for FRP-confined concrete," Construction and Building Materials, vol. 17, no. 6, pp. 471-489, 2003.

[16] K. A. Harries and S. A. Carey, "Shape and "gap" effects on the behavior of variably confined concrete," Cement and Concrete Research, vol. 33, no. 6, pp. 881-890, 2003.

[17] L. Lam and J. G. Teng, "Stress-strain model for FRP-confined concrete under cyclic axial compression," Engineering Structures, vol. 31, no. 2, pp. 308-321, 2009.

[18] G. Mahdavi, K. Nasrollahzadeh, and M. A. Hariri-Ardebili, "Optimal FRP jacket placement in RC frame structures towards a resilient seismic design," Sustainability, vol. 11, no. 24, p. 6985,2019

[19] L. Lam and J. G. Teng, "Design-oriented stress strain model for FRP-confined concrete in rectangular columns," Journal of Reinforced Plastics and Composites, vol. 22, no. 13, pp. 1149-1186, 2003.

[20] Y. Ouyang and N. K. Liu, "Stress strain model for FRPconfined concrete rectangular columns," in Proceedings of the Asia-Pacific Conference on FRP in Structures, pp. 149-154, Hong Kong, December 2007.

[21] S. Rocca, N. Galati, and A. Nanni, "Review of design guidelines for FRP confinement of reinforced concrete columns of noncircular cross sections," Journal of Composites for Construction, vol. 12, no. 1, pp. 80-92, 2008.

[22] L. Wang, W. Xuan, Y. Zhang et al., "Experimental and numerical research on seismic performance of earthquakedamaged RC frame strengthened with CFRP sheets," Advances in Materials Science and Engineering, vol. 2016, Article ID 6716329, 11 pages, 2016.

[23] ACI Committee 440, Guide for the Design and Construction of Externally Bonded FRP Systems for Strengthening Concrete Structures, ACI, Michigan, USA, 440.2R-08, 2008.

[24] T. C. Triantafillou, E. Choutopoulou, E. Fotaki, M. Skorda, M. Stathopoulou, and K. Karlos, "FRP confinement of walllike reinforced concrete columns," Materials and Structures, vol. 49, no. 1-2, pp. 651-664, 2016.

[25] T. Yamamoto and K. Koike, "Study on the influence of cross section size on the compressive strength of concrete circular and square specimens," Proceedings of the Japan Concrete Institute, vol. 34, no. 1, pp. 322-327, 2012, in Japanese. 